\title{
“O Peixe Sempre Vence": lições sobre meio ambiente do ponto de vista de pescadores artesanais
}

\author{
"THE FISH ALWAYS WINS": LESSONS ABOUT ENVIRONMENT FROM THE POINT \\ OF VIEW OF ARTISANAL FISHERMEN

\section{“EL PEZ SIEMPRE VENCE”: LECCIONES SOBRE EL AMBIENTE DESDE EL PUNTO DE VISTA DE LOS PESCADORES ARTESANALES}

\author{
José Colaço Dias Neto *1 \\ zenettobr@yahoo.com.br \\ Recibido: 06/3/2020 Aceptado: 02/8/2020
}

\begin{abstract}
Resumo
Este texto apresenta fragmentos de duas pesquisas etnográficas realizadas em contextos nacionais diferentes, a saber, Brasil e Portugal. 0 objetivo central das investigações foi compreender a percepção dos pescadores artesanais de dois povoados, sobre suas relações com órgãos de gestão e fiscalização ambiental em cada sociedade. Para tanto, a etnografia serviu-se da comparação por contraste com intuito de evidenciar as características mais marcantes de cada contexto pesquisado. Além das diferenças institucionais e culturais, para a surpresa do etnógrafo, a pesquisa também revelou instigantes semelhanças sobre as percepções que pescadores brasileiros e portugueses têm sobre o meio ambiente. Aqui, portanto, serão destacados seus pontos de vista sobre o comportamento dos peixes e a dinâmica dos ecossistemas aos quais estão associados através da faina pesqueira a partir de dois enunciados nativos: a pesca é um jogo e o peixe sempre vence.
\end{abstract}

Palavras-chave: Etnografia, Meio ambiente, Pescadores artesanales, Brasil, Portugal

\begin{abstract}
This text presents fragments of two ethnographic researches carried out in different national contexts, namely, Brazil and Portugal. The investigation purpose was to understand the perception of artisanal fishermen from two villages about regarding their relations with official environmental management in each society. Thus, ethnography used the contrastive comparative method in order to highlight the most striking characteristics of each researched context. In addition to institutional and cultural differences, the research also revealed similarities about the perceptions that Brazilian and Portuguese fishermen have about the environment. Here, therefore, their points of view on the fishes' behavior and the ecosystems dynamics to which they are associated through fishing practices will be highlighted based on two native enouncement: fishing is a game and fish always wins.
\end{abstract}

Keywords: Ethnography, Environment, Artisanal fishermen, Brazil, Portugal

\section{Resumen}

Este texto presenta fragmentos de dos investigaciones etnográficas realizadas en distintos contextos nacionales: Brasil y Portugal. El objetivo central de estos estudios era comprender la percepción de los pescadores artesanales de dos poblados,

\footnotetext{
$1 *$ Departamento de Ciências Sociais da Universidade Federal Fluminense de Campos dos Goytacazes.
}

Tekoporá ${ }^{\circledR}$. Centro Universitario de la Región Este. Universidad de la República (C) Colaço Dias Neto (2020)

Este es un artículo de Acceso Abierto distribuido bajo licencia Creative Commons (CC BY NC 4.0) 
acerca de sus relaciones con órganos de gestión y fiscalización ambiental en estas localidades. De esta manera, la etnografía se sirvió de la comparación por medio del contraste bajo el objetivo de evidenciar las características más sobresalientes de cada contexto. Además de las diferencias institucionales y culturales, para sorpresa del etnógrafo, la investigación reveló impresionantes semejanzas entre la percepción de los brasileños y la de los portugueses sobre el medio ambiente. En el presente texto, por tanto, los destaques serán de los puntos de vista de los pescadores sobre el comportamiento de los peces y la dinámica de los ecosistemas en los cuales se encuentran a través de la fauna pesquera desde dos enunciados nativos: la pesca es un juguete y el pez siempre vence.

Palabras clave: Etnografía, Ambiente, Pescadores artesanales, Brasil, Portugal

\section{Introdução}

Este texto apresenta fragmentos de duas pesquisas etnográficas realizadas em contextos nacionais diferentes, a saber, Brasil e Portugal. A pergunta que dirigiu a observação empírica foi por que, em geral, pescadores artesanais não seguem normas oficiais de preservação ambiental tal como esperam gestores públicos e mesmo ambientalistas com perfil conservacionista? Ao longo do desenvolvimento da pesquisa julguei que a observação direta das práticas pesqueiras, bem como do modo de vida daqueles que dedicam a tal ofício poderiam dar boas pistas para esta problemática.

A primeira área estuda está localizada no norte do estado do Rio de Janeiro. Trata-se de Ponta Grossa dos Fidalgos. Um povoado de pescadores artesanais com aproximadamente 2.000 habitantes, situado na margem norte da Lagoa Feia, dentre os quais 350 pessoas, aproximadamente, vivem diretamente da captura de espécies aquáticas. 0 restante do povoado - sobretudo as gerações mais velhas - encontra-se associado à pesca por seu ingresso nas atividades de vendagem do pescado ou confecção de petrechos como redes, armadilhas e embarcações. Parte da população que não tem ligação direta com a pesca artesanal desempenha trabalhos na região rural das redondezas em ou usinas de cana de açúcar do município de Campos dos Goytacazes. Os pescadores de Ponta Grossa dos Fidalgos, como é comum em outros contextos pesqueiros de águas interiores no Brasil - estuários, charcos, rios, lagoas e lagunas detém historicamente o conhecimento de uma sorte de técnicas e modalidades de captura que, isoladas ou em consórcio, são utilizadas de acordo com os períodos climáticos do ano ou quando se tem alguma predileção pela captura de espécies aquáticas definidas. A relação diária com a atividade e com o ambiente lagunar possibilitou aos praticantes da pesca artesanal em Ponta Grossa um conhecimento refinado sobre os ciclos naturais que marcam as importantes mudanças ambientais através com o passar do tempo, bem como sobre a biologia e a etologia dos peixes e outros seres vivos que compõem o ecossistema da Lagoa Feia.

Desde o início da pesquisa a proximidade com os pescadores do lugar revelou que a relação destes com o Instituto Brasileiro do Meio Ambiente e dos Recursos Naturais Renováveis, o IBAMA, era marcada por tensões e constrangimentos. A partir de meados da década de 1990, o IBAMA pró́be a pesca com o uso de redes nos meses de novembro a março na região do norte-fluminense. A justificativa para tal proibição, de acordo com funcionários do Instituto, é que este período compreende os meses de reprodução da maioria das espécies aquáticas na chamada Bacia Hidrográfica do Leste, área na qual também se localiza a Lagoa Feia. Para além deste período, o IBAMA também tem prerrogativa legal para proibir a captura, em qualquer época do ano, caso identifique alguma situação que configure desequilíbrio ambiental capaz de produzir riscos ao consumo de humano de peixes e outros animais marinhos. Conforme já evidenciado em trabalhos anteriores, a instituição de um calendário ecológico único já há algum tempo vem ocasionando tensões entre os pescadores e o IBAMA 
(Colaço, 2010). O problema, que permanece latente durante o período de pesca liberada, manifesta-se claramente nos meses cobertos pela proibição. Em Ponta Grossa o trabalho de campo durou aproximadamente dez anos - entre 2002 e 2010 - com algumas interrupções, mas marcado pela presença do etnógrafo no povoado que variava dentro este período de finais de semana até dois meses ininterruptos de moradia no povoado.

A segunda área estudada está localizada na costa central portuguesa. Trata-se do povoado da Carrasqueira, localizado no estuário do Rio Sado, no município de Alcácer do Sal. Da capital do país até o povoado percorre-se uma distância de $110 \mathrm{~km}$. A geração mais velha de carrasqueiros se divide entre atividades de captura de peixes e mariscos e trabalhos agrícolas. Atualmente, a Carrasqueira conta com pouco mais de 1.000 habitantes, dentre os quais, aproximadamente 300 são pescadores. Algumas famílias se dividem entre a agricultura e a pesca, atividades que são praticadas em determinados períodos do ano, mas também podem estar conjugadas ao mesmo tempo. A pesca ali desenvolvida possui algumas características bastante singulares, mas, sem dúvida, a maior delas, é o fato que de as companhas de pesca são constituídas por homens e mulheres ligados por laços matrimoniais.

Entre os anos de 2010 e 2011, desenvolvi trabalho etnográfico na Carrasqueira por conta de minha participação em um convênio internacional Capes/FCT Modernidade e Justiça: controvérsias, causas públicas e participação política numa perspectiva comparada Portugal/Brasil. Acompanhei, in situ, as atividades pesqueiras durante quase nove meses e morei no povoado de fevereiro a junho de 2011. Percebi, logo de início, que os pescadores portugueses eram muito críticos em relação à atuação da Direção Geral de Pescas e Aquicultura, a DGPA, no que diz respeito à regulamentação profissional da atividade de captura e à Polícia Marítima, particularmente no que tange à fiscalização a área do estuário do Sado.

A observação direta das práticas de pesca artesanal, nos dois casos, revelou aspectos fundamentais da vida social de pescadores. Características encontradas nestes e em outros povoados pesqueiros tais como observadas também em outros trabalhos de natureza etnográfica. É possível elencar algumas delas nos quatro pontos a seguir:

1) Os pescadores artesanais, geralmente, têm uma percepção apurada do funcionamento do ecossistema nos quais são ao mesmo tempo utentes e partícipes, devido ao exercício cotidiano de suas atividades de captura. A partir de seus conhecimentos, que são transmitidos informalmente de geração para geração, podem, desde que provocados, descrever com detalhes os ciclos hidrológicos e meteorológicos que incidem sobre o Estuário do Sado, bem como os aspectos de sua topografia submersa e o comportamento das espécies aquáticas e não aquáticas (Castro Faria, s/d, Mello y Vogel, 2017, Kant de Lima, 1997; Colaço y Vogel, 2005, Colaço, 2015). 2) Os pescadores artesanais possuem um direito de uso do espaço pesqueiro baseado no costume. Isto ocorre em praticamente todos os territórios de pesca que temos notícia (Colaço et al., 2007, Cunha, 2000, Acheson, 1981, Forman, 1970, Maldonado, 1986). Até onde percebi, na Carrasqueira não é diferente. É possível, portanto, identificar aquilo que Marcel Mauss chamou de Fenômeno Jurídico (Mauss, 2002) na medida em que se observam pescadores partilhando códigos de conduta que dizem respeito a direitos de posse de determinados espaços configurando assim um uso exclusivo ou particularizado dos recursos pesqueiros Neste sentido, questões de ordem moral estão em jogo todo o tempo;

3) Os pescadores artesanais se constituem como um grupo social no qual a incerteza e o risco são características inerentes à sua profissão (Castro Faria, s/d; Mello y Vogel, 2017, Kant de Lima, 1997, Lobão, 2010, Colaço, 2019). Tal característica faz com que este grupo administre a vida como um todo de maneira muito peculiar estabelecendo - em muitas ocasiões - desacordo com certas expectativas engendradas por instituições ou atores sociais que não conhecem 
detalhadamente o cotidiano da atividade pesqueira. Tenho tentado discutir e entender suas noções de tempo (passado/presente/futuro), seus conceitos de vida e morte (humana/animal/ambiental).

4) A reunião dos fatores supracitados, atualmente, quando não são reconhecidos pelo Estados e seus órgãos administrativos pode ocasionar uma série de entraves na promoção de Políticas Públicas voltadas para a preservação ambiental, além de gerarem constrangimentos e tensões com populações que possuem estas formas de relação com a natureza (Vogel y Mello, 1989, Mota, 2004, Prado, 2006, Lobão, 2010 y Colaço, 2019).

5) A descrição das atividades de captura evidenciou como pontagrossenses e carrasqueiros se relacionam com o ambiente em que vivem e trabalham. Mais do que uma atividade desempenhada para suprir sua subsistência física e reprodução material, a dedicação à pesca, nos dois casos, revela, através da etnografia, um mundo repleto de significados conferidos por aqueles que a praticam. Entretanto, esta weltanschauung, que, em muitos aspectos, singulariza a existência destes grupos, quando confrontada com outras formas de pensar e administrar a vida coletiva, encontra problemas. Principalmente, quando o que está em disputa são as qualificações e entendimentos sobre o que é a natureza ou o meio ambiente (Colaço, 2015). Além disso, como será visto à frente, quando tomados de modo cuidadoso e sensível, os enunciados nativos nos remetem a complexas noções de previdência, prospecção, futuro e outras importantes categorias.

\section{Resultados e discussão}

\section{“A pesca é como um jogo”}

Uma metáfora que ouvi muitas vezes durante o trabalho de campo no Brasil e em Portugal caracteriza a pesca artesanal como um jogo. Deste enunciado derivam, também, outras associações. A ideia do jogo trás consigo a definição de onde [em que lugar] ele é praticado, quem são os participantes e quais são as regras.

"Isto é assim. É como um jogo mesmo. Eu posso ganhar e perder. Ganho quando a pesca é boa. Ganho dinheiro posso comprar minhas coisinhas, tudo direitinho. Perco quando a pesca é ruim. Isto não significa que eu perca na vida. Não! No outro dia eu vou lá e ganho novamente. Temos que nos acostumar como isso. A vida é como um jogo. A vida na pesca também." (Alexandre, Carrasqueira)

"Só pode participar disto quem sabe! Quem conhece as regras! Digo, quem conhece a pesca, a lagoa, os peixes $e$ tudo. Quem sabe como é fazer isto aqui todo dia. Porque hoje em dia, não é como no meu tempo. Hoje o cara vem até a lagoa e acha que é pescador. Não é não! Pescador tem que conhecer como as coisas funcionam. Tem que saber sim!." (Dodô, Ponta Grossa dos Fidalgos).

"Acho mesmo que pescador é um bicho competitivo. Ao ponto de furar o olho do outro! É! Ajuda só mesmo aqueles que pescam com ele. Já ajudar os outros? Ah, isso é mais 
difícil. É como um time de futebol. Você joga e ajuda seu time. Porque você quer na verdade ganhar do outro time! Não é? Ninguém gosta de perder!" (Neguinho, Ponta Grossa dos Fidalgos).

O conjunto de etiquetas que organiza o acesso aos recursos pesqueiros, bem como aos espaços mais propícios para a captura, estabelecem limites para a atuação dos pescadores em suas embarcações, configurando um direito costumeiro. Os pescadores conhecem seus princípios. Mas, de todo modo, isto não significa que as mesmas sejam cumpridas à risca. Interpretações ambíguas sobre as etiquetas e mesmo transgressões instrumentalizadas são motivos para tensões e conflitos entre eles. É um jogo, portanto, porque há regras que devem ser conhecidas e praticadas pelos envolvidos.

Mas, quem participa deste jogo? Primeiramente, os relatos apontam para um jogo motivado pela disputa entre grupos de pesca ou companhas. A competição se estabelece a partir da combinação de três fatores: a quantidade e a qualidade pescado e o desempenho do pescador. A quantidade de pescado é contada em quilos ou em unidades. No caso de Ponta Grossa, a unidade é a caixa - engradado de plástico, semelhante aos utilizados em feiras livres que quando estão cheios de peixes chegam a pesar vinte quilos. Já na Carrasqueira trata-se do latão que em seu limite suporta trinta quilos de pescado. A qualidade das espécies capturadas é um fator de distinção neste jogo que pode ou não aparecer associada à quantidade. Na Lagoa Feia, vinte quilos de robalos (Centropomus undecimalis) são mais valorizados do que quarenta quilos de traíras (Hoplias sppou) acarás (Pterophyllum scalare). No Sado, por sua vez, capturar dez quilos de linguados (Platichthys flesus) é mais desejável do que quarenta quilos de charrocos (Halobatrachus didactylus). Em ambos os casos, a qualidade das espécies atualiza a hierarquia dos peixes, de acordo com as avaliações locais que tem como base o conhecimento empírico as dinâmicas do mercado e da venda. Tanto a quantidade quanto a qualidade, como resultado das capturas, estão associadas ao desempenho do pescador que, para obter sucesso, precisa ser reconhecidamente um mestre do ofício. Entre os praticantes, apenas o exímio conhecedor das artes pesqueiras tem habilidade suficiente para mobilizá-las com precisão adaptando-as com precisão às condições ambientais que variam constantemente.

Há, entretanto, uma característica associada ao desempenho: um pescador considerado um mestre de ofício só pode mobilizar técnicas que lhe deem bons resultados porque seus conhecimentos são um dom. Deus, ou forças que estão além de do controle dos homens, são responsáveis pelo funcionamento das coisas mundanas e pelo desempenho afortunado dos pescadores. Embora a relação com o mundo extraterreno seja atualizada de modo diferente quando comparamos os casos de Brasil e Portugal, ou mesmo quando tomamos as formas através das quais cada pescador se conecta com o "divino", a crença numa força maior e superior aos seres humanos é algo comum nos dois povoados pesqueiros estudados. Quando um pescador com dons reconhecidos falha em alguma investida, há a ideia comum de que a penúria é um ensinamento divino, por exemplo. Por isso, o pescador experimentado deve ter calma e paciência para esperar outra nova oportunidade, ainda que a nova investida seja realizada apenas em outro dia.

Este jogo não atualiza a competição apenas entre pescadores. A metáfora aponta para outras direções e incorpora novos personagens. É comum que os pescadores elaborem em suas falas a relação entre eles e os órgãos estatais de gestão ou fiscalização ambiental estabelecendo, dessa forma, a mesma analogia: 
"Ah, aqui é assim! É como gato e rato! Um jogo ou uma perseguição! Se estou na Lagoa e escuto um motor [da lancha da fiscalização ambiental] - motor de lancha, não estes do barco - a primeira coisa que eu faço é me esconder nas tabuas [vegetação] até eles passarem. Eles não podem me ver de longe por causa da cor do barco. Mas eu escuto o motor e me adianto! Não sou bobo! É como gato e rato!" (Ponta Grossa dos Fidalgos).

"Estamos sempre preparados, não é? Ninguém gosta de encontrar a Polícia Marítima. Nem aqueles que estão com tudo certinho. Porque eles sempre vão dizer que tem algo errado. É um extintor de incêndio que não está no lugar certo, é uma vírgula no documento do barco". Prefiro não os encontrar. Quando sabemos por quais sítios eles estão andando, procuramos outro. São eles contra nós e nós contra eles, fazer o que, não é mesmo?" (Carrasqueira).

Aqui, os pescadores constroem a ideia de que os agentes de fiscalização das atividades são oponentes na medida em que percebem sua presença como algo negativo. Precisam criar estratégias para evitar, o tanto quanto possível, os encontros, no Máre ou na Lagoa Feia, com eles. Em Ponta Grossa, por exemplo, meus interlocutores que não param suas atividades no período proibido pelo IBAMA, mudam os horários de saída e chegada da pesca. Optam, na maioria das vezes, pela pesca durante a madrugada, pois argumentam que "o IBAMBA" ou o "meio ambiente" não "anda" pela Lagoa nestes horários: "Eles não conhecem isso aqui. Não é fácil navegar nesta lagoa sem iluminação. Por isso, quando aparecem, é mais perto do início do dia. Nunca de noite [madrugada].

Os carrasqueiros, por sua vez, acreditam que a Polícia Marítima está sempre em desconfiança quanto às suas práticas, sobre as condições nas quais se encontram os equipamentos pesqueiros e em relação aos documentos que permitem o exercício legal da profissão. A maior parte dos carrasqueiros com os quais estive durante o trabalho de campo faz questão de afirmar que andam "sempre em dia" com as exigências da DGPA - as mesmas que são fiscalizadas pela Polícia. Entretanto, pude observar estratégias formuladas pelos pescadores para burlar algumas normas. Alguns pescadores utilizam, por exemplo, a solheira com tamanho de malha inferior aos oitenta milímetros permitidos pelo Regulamento de Pesca, no entanto, não o fazem em toda a extensão das redes. Intercalam, cuidadosamente, malhas de sessenta ou setenta milímetros com aquela permitida. Caso os agentes queiram inspecionar o tamanho das malhas, os pescadores mostram apenas a parte do pano no qual o tamanho é de oitenta milímetros.

"Eu as intercalo. Não uso tantos miúdos abaixo de 80 milímetros não. Mas, se eu não fizer isto, corro o risco de fazer uma maré e voltar sem nada. Isto é que não pode! Então faço assim. Eles são espertos conosco. Por qualquer coisa aplica-nos logo uma coima [multa] altíssima! Temos que ser espertos com eles também". (Carrasqueira). 
O campo no qual este jogo é disputado é, num caso, a Lagoa Feia e, no outro, o Estuário do Sado. Os jogadores são os pescadores e os agentes de fiscalização. Isto define do ponto de vista dos pescadores, os limites físicos e os personagens que constituem aquilo que tenho chamado, analiticamente, de comunidade de vida (Colaço, 2015). Em linhas gerais, a proposta é que este conceito, inspirado na ecologia clássica, seja um dispositivo para entendermos como pescadores artesanais - e outros grupos sociais extrativistas - formulam noções sobre o meio ambiente a partir de suas práticas estabelecendo analogias e associações extremamente complexas que extrapolam as classificações ecológicas mais tradicionais e comuns à disciplina. Tal como a etnografia tem evidenciado, estes grupos sociais possuem teorias bem fundamentadas sobre as formas de interação com elementos constitutivos disso que chamamos de ambiente (envirolment) atualizando, portanto, as relações com a natureza em seus próprios termos. $\mathrm{O}$ conceito ressalta que seres vivos, humanos ou não humanos, estão em constante interação no (e com o) ambiente afetando e sendo afetados, constantemente, por seus encontros. Além dos agentes de fiscalização ambiental, que são incorporados, neste sentido, à comunidade de vida, há também outro elemento dotado de características especiais e investido de agência, vontade e temperamento. Refiro-me, aqui, ao peixe.

\section{"O peixe sempre vence"}

A pesquisa etnográfica realizada entre pescadores artesanais evidenciou que a relação deste grupo com os animais que compõem sua comunidade de vida é bastante complexa. As interpretações nativas sobre o funcionamento da vida animal evidenciam, como a distribuição das espécies é feita em conjuntos relativamente fluidos, mas que são formulados por uma lógica associativa que trabalha dinamicamente qualidades sensíveis atribuídas aos animais.

Características que são usualmente marcadores de distinções entre comportamentos humanos e comportamentos animais (não humanos) são combinadas de modo a dar ordem, do ponto de vista e das práticas dos pescadores. Na Carrasqueira, podemos tomar o Choco (Sepia officinalis) como exemplo deste complexo sistema de classificação. Como disse um interlocutor português: "O choco é tímido. Mas é esperto. Gosta de namorar. É como nós". Em Ponta Grossa dos Fidalgos ouvi muitas vezes que "A traíra (Hoplias sppou) é um peixe tinhoso. Igual a mulher brava! Para pegar, temos que saber lidar com ela!".

O inverso também ocorre. Quando características dos animais aquáticos são utilizadas para qualificar pessoas. "Adoro ameijoas. Adoro ameijoas novinhas. E todo homem tem que ter suas ameijoas, não é mesmo? Os mariscos aparecem como referencias à mulher ou aos órgãos genitais femininos. Em Ponta Grossa, quando alguém comenta "Ih! Lá vem o morobá..." significa que se aproxima um homem considerado chato, ou que a sua presença "contamina" o ambiente - já que o morobá (Erythrinus erythrinus), entre os pontagrossenses, é um considerado um peixe que não tem grande valor comercial, é difícil de ser retirado da rede e ao nadar turva a água o que pode dificultar a captura de outras espécies. 0 mesmo acontece com o charroco (Halobatrachus didactylus). na Carrasqueira. A espécie é considerada localmente como feia (semelhante a um sapo de grandes dimensões) e praticamente não tem valor comercial. Observei muitos de meus interlocutores se tratando por "charrocos" - um modo jocoso desqualificar o outro.

Há mais coisas envolvidas na relação entre pescadores e peixes. A interpretação que pescadores fazem sobre o comportamento das espécies aquáticas as dota de uma agência especial. Acreditam que, assim como eles, os peixes estão constantemente avaliando as situações e respondendo a estímulos dos mais diversos. 
"Pensam por ai que cachorro é o bicho mais esperto do mundo, não é? Mas o peixe é bicho sabido demais. É tão sabido que nem o homem consegue domar ele. Sabe quando vai ser pego. Mas sabe também ser esperto o suficiente para fugir. Assim mesmo como nós fazemos!" (Doba, Ponta Grossa dos Fidalgos).

"Nós escutamos o motor deles [lancha do Batalhão Florestal]. Com o peixe é igual: eles escutam nossos motores e se escondem. Se a água estiver alta é pior ainda. Eles têm mais espaço para andar e se esconder." (Neguinho, Ponta Grossa dos Fidalgos).

"Deus deu a inteligência para todo mundo. Tudo que habita aqui, pelo menos eu penso assim, tem inteligência. Digo tudo que é vivo e se movimenta, lógico! Uma pedra não é inteligente. Mas o peixe é. E pode fazer da pedra sua casa, ou sua cama, ou esconderijo, ou pode comer o limo que gruda nela. Todo peixe tem uma característica. Uns são mais inteligentes outros menos. Mas todos são espertos para fugir do pescador! O problema é que pescador é inteligente também! Ai, vira uma disputa, né?" (Luiz, Ponta Grossa dos Fidalgos).

Os relatos dos pescadores associam características humanas ao comportamento dos peixes. Traços dos dois universos - humano e animal - são misturados. Diferente do biólogo tradicional, que acredita que o peixe responde a estímulos de modo instintivo, os pescadores julgam que o comportamento das espécies assemelha-se aos seus porque ambos, pescadores e peixes, são seres feitos da mesma natureza.

"Eu pesco porque eu tenho que comer e alimentar minha família. O peixe também tem que comer. Faz a mesma coisa que eu. Ele vai comer outros peixes ou outras comidas. Mas, ele igual a nós. Quando ele come, cresce e cria outros peixes. Ele pode passar a vida toda sem ser pescado. Ele pode vir a morrer de velho e não ser pescado. Ele vai lutar pela vida dele e eu vou lutar pela minha. Isto é assim, sempre foi assim e nunca vai mudar! É a lei das coisas." (Joaquim, Carrasqueira).

Uma vez mais, a ideia da luta é vindicada, tal como no relato de Joaquim. Aqui ela envolve o homem e o peixe. Na situação da pesca, os dois fazem parte do mesmo mundo, pois ambos têm do ponto de vista dos pescadores, as mesmas qualidades.

Para o pescador, o peixe é um recurso, na medida em que sua venda nos diferentes mercados é convertida em valores monetários. É, além disso, um alimento e, neste sentido, é a forma mais básica de provimento alimentar das famílias de pescadores. Por fim, o peixe também é alguém com quem se estabelece uma interação mediada pelo interesse da manutenção da vida. Um ente que deve ser respeitado - pois sem sua existência também não existiriam pescadores - mas alguém que pode ser abatido numa disputa considerada justa. 0 pescador lê e interage com o mundo, de acordo com seus conhecimentos sobre ele. Para os 
pescadores, o peixe também "lê" o mundo e interage com os outros elementos da comunidade de vida (outros peixes e outros pescadores, por exemplo) com os mesmos aparatos.

Uma fala de Zé Pedra, proferida na Carrasqueira, por ocasião de uma conversa sobre o futuro do meio ambiente, condensa a interpretação sobre a sinergia estabelecida entre peixes e pescadores:

“Tu já pensaste numa coisa, Zé? Eu sou pescador. Pesco desde miúdo e estes peixes não acabaram. Uma hora tem mais outra hora tem menos. Mas não acabaram por certo. Todos falam por todos os lados que os peixes estão a acabar. Enganam-se! Há peixes sim, senhor! O pescador, por melhor que seja nunca vai pescar todos os peixes do mundo. Nem todos os pescadores do mundo, caso trabalhassem em conjunto, também não iam fazer isso. Quando tu vais ao máre e não trazes nada, naquele dia, o peixe ganhou. Estais a ver? Na verdade, tanto faz o gajo pescar vinte ou duzentos quilos. Nunca irá pegar todos. No fim, o peixe sempre vence!"

Argumento semelhante foi elaborado por Dodô, na ocasião de uma pesca na Lagoa Feia:

"Tem por aí muito mais peixes do que podemos pescar. E a vida de pescador é assim: eu ganho e perco o tempo todo. Os peixes também. Ganham ou perdem. É a vida mesmo. Já tive vezes que pescar doze horas de anzol de bóia. Para pegar sabe quanto? Cinco quilos de traíra. Sabe quem ganhou naquele dia? Não? Eu sei. O peixe ganhou! Porque eu sabia que elas tavam lá num canto que eu sempre pesquei. Por que justamente naquele dia não arrumei nada? Não mudou o vento, não mudou a água. Nada! Ele [o peixe] foi mais esperto que eu. Acontece!"

Se a pesca é um jogo, para meus interlocutores, em suas falas podemos destacar seus principais participantes. São eles os próprios pescadores, os agentes de fiscalização ambiental e os animas aquáticos, em especial, os peixes. Os três coletivos estão em constante interação, animando, em conjunto com outros elementos, o ambiente. A metáfora do jogo aqui, tomada de um modo mais específico, não sugere, de pronto, quem ganha ou quem perde - mesmo que isto esteja no horizonte de todo jogador, em geral, e apareça, constantemente, na fala dos pescadores. Parece apropriado pensar o jogo em questão como um jogo de linguagem - na medida em que ações das partes envolvidas comunicam muito mais do que resolvem as disputas. É justamente a comunicação entre as partes que os aproxima e os distancia, marcando assim, o balanço variável e muitas vezes conflituoso de suas relações.

\section{Algumas noções nativas de previdência}


Tanto as portarias normativas emitidas anualmente pelo IBAMA, quanto o Regulamento de Pesca do Rio Sado enquadram-se, cada uma ao seu modo, no conjunto de dispositivos legais que têm o objetivo de limitar a exploração dos estoques de recursos naturais, em cada ecossistema, de modo a garantir seu acesso para as futuras gerações humanas. Tais dispositivos atualizam formas de controle e utilização de áreas de interesse ambiental com limites definidos. As portarias do IBAMA afetam a chamada bacia hidrográfica do leste, no Brasil, área que compreende quatro unidades federativas. Já o Regulamento de Pesca do Sado é particular à extensão do Rio e incorpora quatro conselhos municipais que o tangenciam.

Aparece embutida nestas normas a ideia de que a ausência de mecanismos que controlem o uso dos recursos marinhos pode afetar objetivamente o desenvolvimento pleno de seres das mais diversas espécies aquáticas. Quadro este que, em longo prazo, pode fazer com que muitas espécies diminuam sensivelmente o número de indivíduos ou, na pior hipótese, deixe de existir. Qualquer um dos prognósticos é percebido como nefasto pela maioria dos ecologistas porque, em sua perspectiva, mudanças abruptas na constituição e no desenvolvimento de espécies aquáticas podem acarretar desequilíbrios irreparáveis aos ecossistemas. Os efeitos ecológicos, neste sentido, se dariam tanto em sua dimensão natural/biológica quanto na social/cultural, pois, entre outras coisas, tais recursos poderiam, também, ser utilizados pelo homem para vários fins.

Portanto, as legislações, tal como se apresentam, trazem, em si, duas importantes noções: por um lado, o reconhecimento da escassez da maioria dos recursos naturais, em especial, das espécies aquáticas. Por outro, ancorada no problema da escassez, há uma construção sobre o futuro da natureza e dos elementos que a compõem. Grande parte da discussão ecológica contemporânea, independente de qual corrente de pensamento faça parte, tem duas categorias referenciais: a escassez (dos recursos) e o futuro (dos ecossistemas) (Brüseke, 2001, Acselrad, 1995).

A etnografia tem mostrado, entretanto, desde seus modelos clássicos até as abordagens mais contemporâneas, que as noções de tempo tal como formuladas por vários grupos humanos, podem variar bastante de acordo com contextos, interesses e experiências coletivas (Mauss, 2003, Evans-Pritchard, 1978, Leach, 1974, Colaço, 2010). Em muitos casos as noções de escassez e futuro formuladas por pescadores artesanais possuem sentidos diferentes daquelas que informam a legislação ambiental vigente.

\section{Abundância e penúria}

Entre pescadores artesanais, só é possível entender a noção da abundância quando esta é contrastada com a noção de penúria. Categorias que, neste sentido, são duas faces da mesma moeda. São condições que estruturam toda a vida da pesca artesanal. Experiências vividas no cotidiano da faina que fazem com que compreendam a pesca - e sua própria existência social como um gradiente que opera para cima e para baixo marcando, dessa forma, o balanço de sua trajetória no mundo. Tal como Mello y Vogel identificaram na pesca lacustre em Maricá, no litoral do Rio de Janeiro:

"Todo pescador sabe que há dias ruins, quadras ruins, tempos de penúria. Por mais e melhor que se pratiquem as pescarias, os esforços permanecem vãos. Nada lhes é, pois, mais estranho do que a ilusão edênica, quando é levado a considerar, reflexivamente, o seu modo de vida 
que, todo ele, repousa sobre as vicissitudes da pesca lagunar." (Mello y Vogel, 2017, p. 298).

Vicissitudes estas encontradas não somente na pesca de águas interiores, mas em todo ambiente ou ecossistema sobre o qual o homem tem relativa capacidade de controle. É possível, tanto utilizando instrumentos de alta tecnologia quanto se baseando em conhecimentos naturalísticos antever, em muitos casos, mudanças atmosféricas ou hidrológicas que podem afetar, objetivamente, as condições nas quais a pesca é realizada, já que tais fenômenos incidem sobre o comportamento das espécies aquáticas.

Para os pescadores, o ambiente natural tem uma lógica que eles entendem por meio dos conhecimentos adquiridos através de sua experiência e observação. Mas, aquilo que move a natureza está, para eles, fora do alcance e do controle dos homens. Os movimentos das águas, a incidência dos ventos ou o comportamento das espécies são a dimensão objetiva de algo que não pode ser visto, quais sejam, a vontade divina e forças sobrenaturais. Sabem, assim, que sua intervenção, diante deste quadro, é muito limitada.

Do mesmo modo, é percebida a dualidade abundância e penúria. Por mais que um bom pescador reúna atributos técnicos reconhecidos e mesmo que seja considerado por outros colegas de ofício, um mestre da arte pesqueira, a incerteza quanto aos resultados cotidianos da captura é uma característica presente na sua trajetória profissional.

"Tanto faz pescar aqui quinze quilos de choco ou quarenta ou oitenta. Tem dia que não apanhamos nadinha. E ainda dizem por ai que vida de pescador é fácil. Quando não pegamos nada quem paga nosso gasóleo? E o nosso esforço? Por isso, para ser pescador tem que se ter paciência. Quando uma maré não dá, outra dá. Há uma verdade sobre as coisas: 'há muito mais marés que marinheiros' [ditado popular]. Portanto, um pescador que não souber conviver com isto, que for muito ansioso ou que acha que pode ganhar tudo sempre, este ai não é pescador!" (Alexandre, Carrasqueira).

Ou, como reafirmava Dodô em Ponta Grossa:

“Eu não já lhe disse: tem dia que é o peixe que ganha! Nós pescadores, não ganhamos nada. Temos é que agradecer [a Deus] mesmo assim porque fomos e voltamos vivos $e$ bem. E que temos saúde para continuar e tentar a pesca no dia seguinte. Isso sim".

As narrativas indicam que os pescadores aceitam com resiliência os resultados da pesca. Percebem que têm o dom de serem pescadores - objetivados em seus conhecimentos naturalísticos e na energia que despendem para realizarem seu ofício. 0 usam, portanto, para prover o sustento material de suas famílias. Mas sabem que o funcionamento das coisas do mundo não depende diretamente deles. E que tanto faz um dia ganhar muito e outro dia não ganhar quase nada. Suas noções sobre abundância e penúria podem, dessa forma, nos levar a discussão em torno da escassez. 
Quando questionados sobre se há ou não escassez de peixes, muitos de meus interlocutores constroem argumentos como:

"O peixe não acaba! Pode acabar num lugar e aparecer em outro. Pode aparecer ou desaparecer. Mas acabar o peixe não acaba não! Ah, tem muito peixe. É mais fácil o pescador se acabar, na cachaça do que o peixe se acabar na Lagoa [Feia]! Escute o que eu tô te dizendo!" (Pudim, Ponta Grossa dos Fidalgos).

"Olhe, tenho para mim que, se todos pescarem muito em todos os lugares, o peixe pode desaparecer ou diminuir. Mas, cá na Carrasqueira, não pescamos tanto assim, estais a ver. Olha a quantidade de pescadores hoje! As pessoas estão a sair da vida da pesca por outras razões. Mas não podem dizer por ai que não há mais peixes! Isso é mentira!" (Minda, Carrasqueira).

"O que tem por ai, Zé, é gente preguiçosa. Aqui em Ponta Grossa, quase ninguém pesca de anzol de bóia. Sabe por quê? Porque é muito mais cansativo. Exige muito mais talento e força do pescador. A turma só quer saber de rede de espera [minjoada] porque já não se pode trolhar em toda a Lagoa [Feia] como no tempo dos antigos. Então eu lhe digo: tem é preguiçoso. E não falta peixe!" (Cau, Ponta Grossa dos Fidalgos).

"O bom pescador sempre vai encontrar o peixe onde ele estiver." (Joaquim, Carrasqueira).

As ideias sobre a escassez do pescado, nos tempos atuais, são contextuais. Em primeiro lugar, são formuladas a partir da perspectiva da comunidade de vida, tal como apresentada anteriormente. Isso significa dizer que para a maioria dos pescadores, os peixes não são finitos, porém, o "mundo" habitado por eles é. E o mundo no qual estes pescadores habitam, em conjunto com peixes e outros elementos, é o mundo de suas experiências práticas - onde vivem, interagem e desenvolvem suas atividades profissionais. É este universo que os interessa.

Por isso, nesta perspectiva, muitos dos discursos de preservação ambiental parecem vazios de sentido ou distantes para meus interlocutores. Seus relatos mostram que a constituição desta comunidade de vida é marcada pela trajetória dos elementos reconhecidos como participantes de uma teia de interações circunscritas a um espaço com limites relativamente fechados. E por isso marcado pela proximidade. Seja na Lagoa Feia ou no Rio Sado. A "escassez do estoque pesqueiro na Europa Continental" e a "diminuição dos indivíduos novos das espécies nativas do centro do Brasil" são informações que, mesmo vinculadas em programas oficiais de conservação ambiental formulados por órgãos oficiais, parecem, para eles, bastante longe de suas experiências objetivas com a natureza. 


\section{Algumas conclusões sobre presente, futuro e meio ambiente do ponto de vista nativo}

Talvez por isso recaia, ainda, sobre muitos povoados pesqueiros a ideia de que elas são "predadores da natureza" ou "imprevidentes". Suas percepções sobre o que são os recursos naturais, suas quantidades e seu destino muitas vezes estão em desacordo com as lógicas de preservação ambiental formuladas sob outras bases compreensivas - as mesmas que informam parte significativa da legislação ou mesmo as políticas públicas sobre o assunto.

É comum que os atuais mecanismos regulatórios sejam influenciados por uma noção de futuro construída conjunturalmente. A modernidade trouxe consigo a ideia de que, a partir da ciência, do cálculo e do planejamento racional, o futuro pode ser relativamente controlado. Estes elementos forneceram ao "homem moderno" um pouco mais de segurança em relação à vida e, além disso, lhe dão, supostamente, a capacidade de projetar, em bases consideradas sólidas, os rumos para algo que ainda não experimentou; para um tempo que ainda será feito. Daí vem toda a concepção de que uma intervenção política instrumentalizada pode garantir que o futuro da sociedade humana seja marcado por menos sofrimento coletivo tal como ela experimentou em outros períodos (Giddens, 1991).

Entretanto, esta concepção abstrata de futuro, em vários aspectos, não se encaixa, semanticamente, nas percepções que grupos de pescadores artesanais têm sobre estes assuntos. Seguem algumas elaborações nativas:

"Presente para mim, é aqui e agora. O passado já passou. Era melhor, né? Agora o futuro... ah! Este ninguém sabe. Pra mim não existe. Pode existir para meus filhos e netos, talvez. Pra mim não. Por que vou morrer logo, né? Pescador morre velho, mas morre!" (Maneco, Ponta Grossa dos Fidalgos).

"No futuro, tudo isso vai se acabar mesmo. Eu vou me acabar, você vai se acabar. Tudo vai! É a lei da vida. Uma hora estamos vivos, outra morremos. Novo ou velho. Mais acho que a gente morre mais de velho mesmo. Com a natureza é igual: podem tentar controlar, fazer o que quiser. Ela vai acabar também. Não agora, mas vai acabar sim! Nada é pra sempre neste mundo!" (Cáu, Ponta Grossa dos Fidalgos).

"Não deixamos nada para os nossos filhos além de educação para seguir a vida adiante quando já não estivermos mais cá neste mundo. Trabalhamos agora para deixar para eles uma vida um pouco melhor do que foi a nossa. Porque a nossa foi muito dura. Deixamos uma vivenda, o barco - caso queiram vender - umas terrinhas e só. Porque nunca sabemos mesmo como vai ser o futuro." (Deolinda, Carrasqueira). 
Tomados em conjunto, os relatos sugerem certo fatalismo em relação ao futuro. Por um lado, uma ideia compartilhada de que "tudo vai acabar mesmo" e que não há como conter, por voluntarismo, esta condição. Por outro, se não existe uma noção que projete "a sociedade" neste tempo que ainda não chegou, entre os pescadores, a concepção sobre o futuro recai sobre a existência, objetiva, das gerações mais novas. A ideia do tempo aqui é marcada por um corte geracional entre os pais e os filhos sendo, o primeiro grupo protagonista do presente e o segundo, de um tempo que está por vir. Não é, portanto, a sociedade com suas qualidades abstratas que vai figurar no futuro e para a qual os recursos naturais escassos devem ser assegurados. 0 que está em jogo aqui é a reprodução social e material da família. Isto é o futuro para eles.

No caso dos pescadores da Carrasqueira onde quase não há renovação de quadros na pesca artesanal local, os pescadores ressaltam, de variadas formas, o desejo de deixar para seus filhos outro tipo de patrimônio que não os recursos naturais:

"Daqui há pouco tempo não restarão mais pescadores aqui, como estais a ver. Somos os últimos. Já não importa se teremos peixes ou não. Isto vai virar um lugar de turistas. Estou a dizer. Venha aqui novamente daqui ha alguns anos para veres. Estou certo. Algumas gentes vão manter seus barcos para passear com os turistas e só. Os peixes, se não vierem de outros lugares, podem vir da aquicultura. É, isto é assim." (Diamantino).

"Não podemos deixar quase nada do mundo para nossos filhos, porque estas coisas não nos pertencem. De quem são os peixes, as plantas e tudo mais que está por ai? São de Deus, pois. Do mundo! Não temos nenhum controle sobre isso. Se Ele quiser acabar com tudo aqui, de uma hora para outra, acaba. O que podemos fazer? Nada! Por isso eu digo: só podemos deixar para nossos filhos a vontade de lutar pela vida, de ser certo, gente correta, trabalhadora. Este é o patrimônio. Não é natureza nem nada!" (Fátima).

Mesmo em Ponta Grossa dos Fidalgos, onde há mais jovens envolvidos com a pesca do que no povoado português, tal percepção não difere tanto. Nas palavras de Dodô:

"Criei oito filhos com a pesca. Construí duas casas. Vão ficar para eles. Bolê e Julio devem ficar com meu barco e minhas coisas. São os únicos que pescam agora. Não sei se vão continuar pescando. Julio diz que não quer, que quer trabalhar em Campos ou outro lugar. Vamos ver. O certo é que já fiz minha parte. Tenho a consciência tranquila! Se o mundo acabar, se o peixe acabar aí já não é comigo, né? Com alguma coisa eles ficaram."

A natureza é para os pescadores dos dois povoados uma comunidade de vida da qual fazem parte em conjunto com outros elementos. Mas é também considerada uma fonte de recursos. Para os carrasqueiros "o máre é um lugar de trabalho". Para os pontagrossenses, "é o 
trabalho duro de pescador na Lagoa Feia que sustenta a vida". 0 peixe, por sua vez, conforme apontado antes, é um símbolo complexo. De acordo com cada situação ele pode ser percebido de um modo: como um recurso monetário, como um alimento ou como um adversário do pescador.

Em resumo, os recursos naturais, tais como assim designados no vocabulário técnico/acadêmico e ecológico, para os pescadores envolvidos nesta pesquisa constituem uma realidade que se objetiva no tempo presente. Não demonstrar preocupação ou interesse na sua conservação (outra categoria de linguagem produzida no contexto técnico/acadêmico) para o futuro "da sociedade" não os torna, simplesmente, imprevidentes. Nesta ótica, consideram que não podem prever o que vai acontecer com peixes, mariscos e outros animais aquáticos em um tempo que ainda não experimentaram. Sua única ligação com este tempo se objetiva através da existência dos filhos. Consideram, portanto, que tem responsabilidade com a criação da prole, tanto do ponto de vista material quanto moral. Entretanto, como apontam os relatos, não associam a continuidade, ao longo do tempo, dos recursos naturais aquáticos, por exemplo, com a continuidade da família.

\section{Referencias}

Acheson, J. (1981). Anthropology of Fishing. Annual Review of Anthropology (pp. 275-319). Mississauga, Canada: University of Toronto.

Acselrad, H. (1995). Externalidade Ambiental e Sociabilidade Capitalista. In: Cavalcanti, C. (Org.). Desenvolvimento e Natureza. Estudos para uma sociedade sustentável (pp.128-138). São Paulo/Recife, Brasil: Cortez/Fundação Joaquim Nabuco.

Bidegain, P., Fontenelle, C.R. y Soffiati, A. (2002). Lagoas do Norte Fluminense - Perfil Ambiental. Rio de Janeiro, Brasil: SEMADS.

Brüseke, J. (2001). O Problema do Desenvolvimento Sustentado. In: Cavalcanti, Clóvis (Org.). Desenvolvimento e Natureza: estudos para uma sociedade sustentável. São Paulo, Brasil: Cortez Editora.

Castro Faria, L. de. (s/d). Os Pescadores de Ponta Grossa dos Fidalgos: Um Estudo de Morfologia Social. Conforme originais incorporados ao acervo do Museu de Astronomia e Ciências Afins MAST/CNPq, no Observatório do Valongo, Rio de Janeiro/RJ.

Colaço, J. (2010). Las variaciones estacionales y los conflictos en el pueblo pesquero de Ponta Grossa dos Fidalgos, Rio de Janeiro. Cuadernos de Antropología Social 31, pp. 169-187.

Colaço, J. (2013). É na Lota ou à Candonga? Notas sobre a venda de peixes na costa portuguesa. Confluências: Revista Interdisciplinar de Sociologia e Direito. 15(1), pp.23-32.

Colaço, J. (2014). É Peixe ou Não É? Notas sobre a classificação dos animais em uma aldeia de pescadores em Portugal. Ruris 8, pp. 31-51.

Colaço, J. (2015). Quanto Custa Ser Pescador Artesanal? Etnografia, relato e comparação entre dois povoados pesqueiros no Brasil e em Portugal. Rio de Janeiro, Brasil: Garamond. 
Colaço, J. (2019). Costume e Resistência: elementos para uma política do enfrentamento entre pescadores artesanais da região norte-fluminense. In: Colaco, J. (Org.). Pesca Artesanal no Norte Fluminense: estudos de caso sobre meio ambiente, conflitos e resistência de um modo de vida (pp.237-255). Rio de Janeiro, Brasil: Autografia Editora.

Colaço, J. e Vogel, A. (2005). O Duro, a Pedra e a Lama: A etnotaxonomia e o artesanato da pesca em Ponta Grossa dos Fidalgos. Revista Antropolítica, 19(2), pp.165-190.

Colaço, J., Vogel, A. e Moura, C.A. (2007). História de Pescador: o direito do ponto de vista nativo. Revista Arquivos de Direito, Ano 7, 1(9), pp.57-79.

Cunha Delgado, G. (2000). Pescadores e Surfistas: uma disputa pelo uso do espaço da Praia Grande. Niterói: Dissertação apresentada ao Programa de Pós -Graduação em Antropologia e Ciência Política da Universidade Federal Fluminense para obtenção do Grau de Mestre. (O trabalho em sua versão integral encontra-se disponível para consulta na biblioteca do Instituto de Ciências Humanas e Filosofia da Universidade Federal Fluminense/ICHF/UFF).

Evans-Pritchard, E. (1978). Os Nuer: uma descrição do modo de subsistência e das instituições políticas de um povo nilota. São Paulo, Brasil: Perspectiva.

Forman, Sh. (1970). The Raft Fishermen. Tradition and change in the Brazilian peasant economy. Bloomington \& London, U.S.A: Indiana University Press.

Giddens, A. (1991). As Consequências da Modernidade. São Paulo, Brasil: Unesp.

Kant de Lima, R. (1997). Os Pescadores de Itaipu. Meio Ambiente, conflito e ritual no litoral do Estado do Rio de Janeiro. Niterói, Brasil: Eduff.

Lobão, R. (2010). Cosmologias Políticas do Neocolonialismo. Como uma política pública pode se transformar numa política do ressentimento. Niterói, Brasil: Eduff.

Leach, E. (1974). Dois Ensaios a Respeito da Representação Simbólica do Tempo. I) Cronos e Crono II) O Tempo e Os Narizes Falsos. In: Leach, E. Repensando a Antropologia (pp.191-211). São Paulo, Brasil: Perspectiva.

Maldonado, S. C. (1986). Pescadores do Mar. São Paulo, Brasil: Ática.

Martins, R., Carneiro, M. y Rebordão, F. (2004). Contribuição para o conhecimento das artes de pesca utilizadas no Rio Sado. Publicações Avulsas do IPIMAR n. 10. Lisboa, Portugal: IPIMAR/Ministério da Agricultura, Pescas e Florestas/INIAP.

Mauss, M. (2003). Ensaio sobre as Variações Sazonais da Sociedade Esquimó. In: Mauss, M. Sociologia e Antropologia. São Paulo, Brasil: COSACNAIFY.

Mauss, M. (2002). Manuel d'ethnographie. Paris, France: Éditions Payot. 
Mello, M. A. da Silva y Vogel, A. (2017). Gente das Areias: Sociedade, História e Meio Ambiente no Estado do Rio de Janeiro. Niterói, Brasil: Eduff.

Motta, F. Reis. (2004). 0 que Não é de Um é de Outro: Conflitos e Direitos na Ilha da Marambaia. In: Acselrad, Henri (Org.). Conflitos Sociais e Meio Ambiente no Estado do Rio de Janeiro. Rio de Janeiro, Brasil: Relume Dumará/FASE, pp. 93-125.

Pinto, R. (2019). Hoje é dia de feira: apontamentos sobre a feira da roça e a feira e a Feira do Peixe em Campos dos Goytacazes. In: Colaço, J. Pesca Artesanal no Norte Fluminense: estudos de caso sobre meio ambiente, conflito e resistência de um modo de vida (pp.163-204). Rio de Janeiro, Brasil: Autografia.

Prado, R. M. (2006). Depois que entrou o IMBAMBA: Percepção de questões ambientais na Ilha Grande. In: Prado, R. (Org.). Ilha Grande. Do Sambaqui ao Turismo. Rio de Janeiro, Brasil: EdUERJ, pp. 221-251.

Soares, A. L. A. P. (2004). Caracterização da Pesca no Estuário do Sado. Relatório de estágio do curso de Licenciatura em Biologia Marinha e Pescas da Universidade do Algarve.

Taylor, Ch. (2000). Seguir uma Regra. In: Taylor, Ch. Argumentos Filosóficos. São Paulo, Brasil: Edições Loyola, pp. 181-196.

Vogel, A. y Mello, M. A. da Silva (1989). O Experimento de Tobiki: Algumas Reflexões Sobre a Didática Magna da Prosperidade. Fórum Educacional. Rio de Janeiro: FGV. pp. 3-25. 